\title{
DLR
}

\section{Aerogels for foundry applications}

Since many years aerogels are especially developed for foundry applications at the German Aerospace Center (DLR) in Cologne/Germany. The newest developments are AeroAdditives - nanostructured aerogels in granular form. The addition of 0.5 up to 5 vol.-\% of AeroAdditves to any common sand-binder system leads without any further changes to enormous improvements of the cast part quality by unchanged quality of the sand cores. The positive effects are caused by an enhanced gas permeability of the sand cores and an extremely high absorption potential for casting gases by aerogels. Smooth surfaces with reduced roughness are pointed out. AeroAdditives open possibilities of cast part design which will give new impulses.

Hall 12/Stand G 23

www.dlr.de/mp

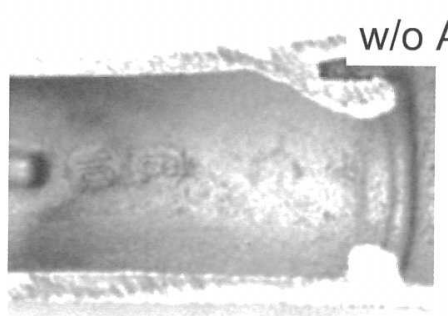

Brass

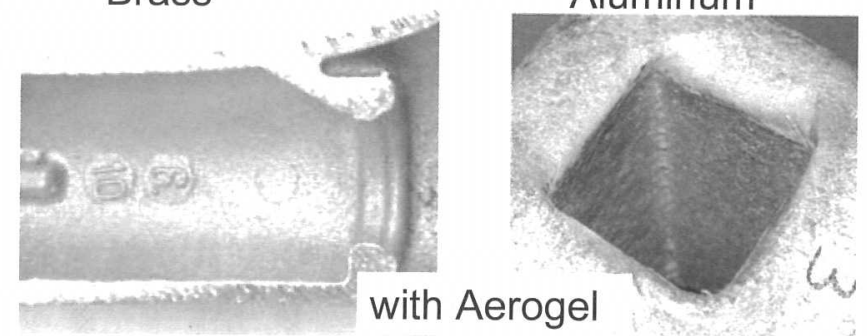

Obvious improvement of casting parts quality by the use of AeroAdditives. Above: Brass and aluminium castings without Aerogel, below: Castings with Aerogel (Photo: DLR)



